\title{
How Individual Experiential Fit Drives Mobile Platform Cocreation- supportive Behaviours in a Digital Business Ecosystem
}

\author{
MY-TRINH BUI \\ International School, Vietnam National University Hanoi, Vietnam \\ VIETNAM \\ DON JYH-FU JENG \\ Graduate Institute of Technology, Innovation \& Intellectual Property Management \\ National ChengChi University \\ TAIWAN \\ THI MAI LE \\ International School, Vietnam National University Hanoi, Vietnam \\ VIETNAM
}

\begin{abstract}
Digital business ecosystems and platforms have emerged as collaborative tools, but few studies have investigated the competitive value that defines winners in the competition among platforms. This study examines the effects of experiential fit on identification, cocreation reward, and cocreation-supportive behaviours by considering the theories of organisational fluidity, service-dominant logic, and social support. Data collected from 1,090 respondents are analysed using AMOS and SPSS. The service-dominant approach is incorporated with a dynamic view of individual value fit to explore user identification, rewards, and cocreation value. The statistical results reveal that a mobile-based ecosystem may provide value convergence for its users (i.e., experiential fit) and thus enable value reservation (i.e., identification), achievement (i.e., cocreation reward), and value dissemination (i.e., cocreation-supportive behaviours). This study offers a new dynamic approach regarding cocreation-supportive behaviours for the digital business ecosystem literature.
\end{abstract}

Key-Words: - Digital business ecosystem, Mobile platform, Experiential fit, Identification, Cocreation

Received: February 16, 2021. Revised: July 21, 2021. Accepted: July 28, 2021. Published: August 4,

2021.

\section{Introduction}

Business ecosystems are increasingly enabled by technological innovation, regulatory changes, and competitive business models. Approximately US $\$ 60$ trillion of global corporate revenue will have been mediated by ecosystem platforms by 2025 [1]. Mobile platforms facilitate the spatial exploration of potential customers, the entrance of new suppliers, and the use of underutilised inventory to minimise transaction overheads and maximise customer adoption of services. Mobile applications are generally commercialised through application platforms, which accounted for the majority of the global mobile app revenue of over US\$365 billion in 2018. In 2023, app revenue is expected to exceed US $\$ 935$ billion [2]. Cross-industry business has been organised and integrated into mobile platform service ecosystems such as those in video game consoles, education services, electronic retailing, hospitality and transportation services, financial services, medical and healthcare services, and crowdfunding. Multisided ecosystem mobile platforms are designed to generate input resources including participation, interaction, experience in coproduction, and cocreation of new services and outcomes $[3,4]$. The delivery and creation of new services require stakeholders' mutual dependence to provide value to the ecosystem [5]. Conventionally, researchers have conceived of individual firms and entrepreneurs as producers (i.e., value initiators) and customers as consumers of product and service offerings (i.e., value adopters) [6]. Ecosystems, which provide a dynamic view of mobile market interactions, have been employed for value cocreation between firms and consumers by eliminating producer-customer boundaries; they thus contribute to service innovation [7].

Research has suggested that value is cocreated by firms and customers [8] and thus becomes a cooperative asset for all parties $[9,10]$. Cocreation research has examined how firms manage their 
business landscape and mobilise contextual value signifiers to communicate with people various lifestyles, to direct behaviour, and to shape platform services to fit the expected experience [11]. The current study focuses on the value created by individual consumers. We argue that cocreated value generates platform assets in the following respects. User flow experience has become increasingly critical in ecosystem platform research [12], but few studies have investigated experiential fit. Experiential fit merits examination because it represents the instrumental conduit linking identification and cocreation rewards with supportive behaviours, which are valuable assets to the ecosystem. The aim of this paper is to fill a considerable void in the literature by investigating the effect of experiential fit on reward, identification, and cocreation-supportive behaviours. Our work integrates the servicedominant (SD) logic, social support, and social dynamics literature and proposes a framework of congruence-conservation and achievementdissemination. The study focuses on users and customers as focal stakeholders who experience ecosystem platforms via mobile applications. How users identify with platforms, obtain cocreation rewards, and support platform cocreation through their supporting behaviour is investigated.

\section{Literature Review}

\subsection{Social Dynamics of Value Fluidity in Mobile-Enabled Business Ecosystems}

Mobile information and communication technologies (ICTs) have opened up a plethora of diverse business prospects. In turbulent times, the environment can be complex and fluid due to changing geographic, temporal, and structural distinctions [13]. Digital platforms are wrapped up with the user participation as dynamic members. The emphasis on users has however inclined to moderate the mechanical, technical and commercial impacts that have determined the development of digital platform to compoundly and manageably varied commercial actors. The development of the marketable business and industry participation of key platform players leads to the foundation of its service ecosystem. Facebook launched commercial services through its messenger and now develop its cryptocurrency. LinkedIn has increasingly prolonged its networking competences to the providing of expertise and employing services to many firms. TripAdvisor comercilizes traveling packages cross the whole trip charge, permitting users to evaluate and make comparation of lodging or cafeteria information and make their reservation. These evolutions of social media players are connected with the increasing participation of the platform within a grander ecosystem of various services. The ecosystem is a definition to denote the collaborations and complementarities attained between the events, properties or productivities of diversified firms $[14,15]$.The dynamic of rules, members, and experiences in online societies is known as fluidity and changes continuously. Ecosystem fluidity is beneficial to the ability to cocreate and build group value $[16,17]$. The fluidity of technology-based communications and the formation of online group associations may be associated. Traditional organisations become more fluid as a result of digitalisation through Internetbased platforms. The principle of fluidity also refers to the dynamic distribution of value and capital as market inputs and outputs [18]. The value identified by "passion, time, personality, social disembodiment of thoughts, socially undefined identities, and transient convergence" flows sequentially and rapidly into new shapes [18]. The web connects users across geographical and time limits, making determining who is in and who is out of online groups difficult. Many people in online communities go through periods of exit and return, which evolve over time. Individual involvement varies from being strongly dedicated to a single form to engaging in a multitude of forms at varying times. Although fluidity can have negative consequences such as the lack of a sense of identity and effectiveness, which can cause confusion and conflict, Faraj et al. [18] argued that fluidity in online communities promotes cooperation if the group reacts in ways that facilitate engagement. In scientific research, the principle of "meaning fluidity" has attracted little interest. In theory, the flow of value is uncertain and context-based, implying that fluidity can be strongly influenced by the social and cultural context. Mobile ICTs promote teamwork, allow for the fluidity of capital and meaning, and enable participant experiences, all of which can contribute greatly to the generation of creative and successful behaviours.

The present study suggest that social dynamics enable four collaborative functions of an ecosystem. The stimulating role's function enables members to take on particular positions that can transform a potentially negative scenario into something more constructive experience and fit to the context. The information conveying function helps stakeholders keep all fluid partners up to date on the current state of information and identify with the ecosystem. The 
dynamically changing border's function may change boundaries in ways that prevent or allow users to enter and exit the ecosystem-based communities at specific times. The more rewards are initatiated, the more positive dynamic changes the ecosystem enhanced. The fourth function, evolving technology affordances, indicates how online ecosystem societies iteratively modify the tools they use in ways that are influenced by iteratively improved social norms and value cocreation. Because of its fluidity, these digital platforms assist the online world in socially and functionally responding to updates, ensuring that the ecosystem community does not vanish. Although the fluidityattribute provide a positive starting point for understanding the relationship between participants in nontraditional organisations, further research is required to expand and comprehend the preliminary research efforts into different forms of ecosystem communities.

\subsection{Value Cocreation with Customers in Mobile-Enabled Business Ecosystems}

Although businesses involve their clients in their digital market environment, value cocreation is a key term in SD logic [19]. SD logic focuses on the operation of operant assets including abilities and experience ("those who act upon other resources;" [20], pg. 148). Actor-generated structures and institutional frameworks coordinate value cocreation [7]. The value is facilitated through the digital platform, which becomes an essential instrument integrating all activities and interactions between firms and their contributors in the ecosystem network $[8,21]$. Participatory experiences in online communities contribute to a complex network of service sharing those senses and responds within an environment governed by agreed-upon rules to control the boundary and exchange (Vargo and Lusch, 2010, 2016). Individual participants and the sponsoring organisation connect and learn from each other through online communities. To distinguish themselves in a competitive market, businesses should plan their platform application as a mechanism to provide knowledge and emotional support to their clients [22]. Interactions between the company and a client can become available to all users in an ecosystem digital environment. In an online community, harmonious partnerships can be established by deciding upon firm and individual participant rules. When the company concentrates on interactions, it broadens its value enablement activities to involve value cocreation with clients. For example, ecosystem companies tailor network applications to customer needs, allowing these applications to send messages of support, care, and motivation. Customers should be socialised to the market method, which turns them from passive beneficiaries of firm value into productive value producers [23]. Gensler, Völckner [24] argued that digital platforms can become a socialisation instrument for consumers, helping them communicate with firms and cocreate value in such a way that the consumers become supporters of the firm. The unique customership and broader functionalities of the ecosystem platform shape the social dynamism and interaction characteristics of customers. Cocreation is more volatile in digital businesses than in other businesses. However, a firm and its customers are likely to become cocreators if they have direct contact [25].

\subsection{Individual Experiential Fit to the Ecosystem Platform}

Adding weight to boundary resources, platforms direct the creativity of ecosystem members to fit as value-added personal environment. A new approach to value cocreation has been proposed that shifts the emphasis away from concrete outputs and toward fluidal SD logic [20]. The updated SD logic viewpoint [7] defines value cocreation as behaviour by several actors (possibly unaware of each other) that support each other. The platform thus transforms heterogeneous resources into newly demanded and valuable assets. In an ecosystem, the configuration (including its technical core and derivatives) of the digital platform should be aligned with the characteristics, core values, attributes, and identities of the user base [26]. The configuration is the aggregation and alignment of the platform's functional components to generate expected performance. The current study proposes that in the value creation process, users' functional and emotional experience is determined by how well user expectations are met by an online platform, with the experience including that of the system, information, service, and emotion [27, 28]. A functional fit allows the ecosystem that produces information, system accuracy, efficiency, consistency, and service effectiveness to support customers and thereby results in a high-performance platform. Experiential fit is determined by the expected practices and experiences of information, service, system, and emotion, which are proximate to actual platform performance [29]. Because of a lack of face-to-face collaboration and control, dispersion may weaken the connection between individuals within an ecosystem [30]. However, high-performance platforms can develop customer experiences, practices, and levels of activation [30], 
which influence user identification with the mobile platform ecosystem. Therefore, experiential fit with a platform's information, service, and system can influence a user's identification with the ecosystem.

Hypothesis 1. Individuals with higher levels of experiential fit have higher levels of identification with the firms in an ecosystem.

The integration of new resources is precious, unique, and nonreplicable. The value of the alignment is attributable to the cooperation between the service provider and users. Technical and emotional attributions can leverage the quality of a platform's information, service, and system, and interactions thus result in new cocreated-valueadded derivative assets. The instrumental platform offers optionality, flexibility, and privilege for users. The more likely that users' requirements can be met, the more likely the users are to obtain considerable positive value from cocreation and collaboration [31]. Self-organisation, interaction and interdependence, coevolution, and development of the digital ecosystem have received the most research attention. Digital infrastructures and mobile technologies, in an organisational sense, may be suitable for active people located over different areas and who tend to collaborate to perform supportive tasks in a flexibility-oriented system and interconnected digital culture [32]. Participatory users and firms are connected to a boundary-less and less hierarchical network that becomes an online fluid ecosystem. Individual users can sense and respond to service sharing in a platform that operates under arranged-upon regulations to govern the sharing application and supporting activities [7, 33]. Individual participants and firms connect and benefit from each other. Interactions between a company and its client can become available to all users in an ecosystem digital environment. The same degree of online community's collaboration between members and their peers could be reached, which is apparent to the firm. The online ecosystem can achieve harmonious partnerships and rewards through a consensus between the firm and individual members. Therefore, experiential fit to the platform is predicted to influence cocreationsupportive behaviours and cocreation rewards.

Hypothesis 2. Individuals with higher levels of experiential fit exhibit higher levels of cocreationsupportive behaviours.

Hypothesis 3. Individuals with higher levels of experiential fit experience higher levels of cocreation rewards when they participate in projects with ecosystem firms.
2.4 Identification with the Ecosystem Firm Sharing-based, heterogeneous, and expanding digital platforms are generating a collection of human and social categories, affective commitments, social ties, and networks that are not geographically bounded [34, 35]. A technological backbone and derivative assets help platforms deliver dynamic value. The ecosystem enables collaborative value creation and supportive behaviours through the efforts of independent ecosystem constituents [14] to interact, influence, connect, meet personal needs, and obtain desired benefits [5]. This value-added characteristic increases the unpredictability of innovative contributions to an ecosystem [36, 37] and thus provides benefits to individuals, effective marketing, and business opportunities. Individuals clearly perceive the importance of networking nodes and relationships; therefore, they are likely to share knowledge (through feedback for improvement and innovation), to provide referrals (i.e., introduce new customers), and to provide support to others in the interactive ecosystem [38, 10]. An individual's contribution to the ecosystem is repeated to the extent that the individual feels indebted to the ecosystem and thus identifies with it $[39,40]$. Thus, identification mechanisms can lead to the establishment of norms, obligations, and contributions to the ecosystem.

Hypothesis 4. An individual's level of identification with an ecosystem firm is positively related to the levels of their cocreation-supportive behaviours.

\subsection{Cocreation Reward for a Cocreated Project with the Ecosystem Firm}

Socially constructed open platforms have specialised tools for economic exchange [20] and value cocreation between firms, external parties, and other users in the ecosystem. Service providers are contributors who support consumers or other individuals to engage in purchasing, to achieve goals, and to satisfy demand [10]. Traditionally, value has been viewed as being created and transmitted by firms. The present study argues for a different perspective of value as being customercentric and cocreated by service providers and individuals [20]. Cocreation can be defined as joint activity between service providers and individuals that involves role exchange, resource alignment, and value identification [25]. Customersincreasingly perform tasks that traditionally were performed by firm employees, and ecosystems increasingly involve individuals in service cocreation and delivery $[41,42]$. The rewards of the value creation 
include components such as meaningfulness, collaboration, contribution, recognition, and affective response. Meaningfulness is the extent to which the service's importance and worth is expected to increase as a result of the cocreation process [43]. Furthermore, individuals seek inspiration, authenticity, belonging, specific value, and purpose [44]. Reward from collaboration emerges from the alliance of shared awareness, common vision, reciprocal relationships, and functional interdependence [6] to create value, which leads to improvement of both user experience and firm performance [45]. Studies have suggested that the value produced through cocreation may generate platform cocreation-supportive behaviour $[46,40]$.

Hypothesis 5. Individuals who experience high levels of cocreation reward exhibit high levels of cocreation-supportive behaviour.

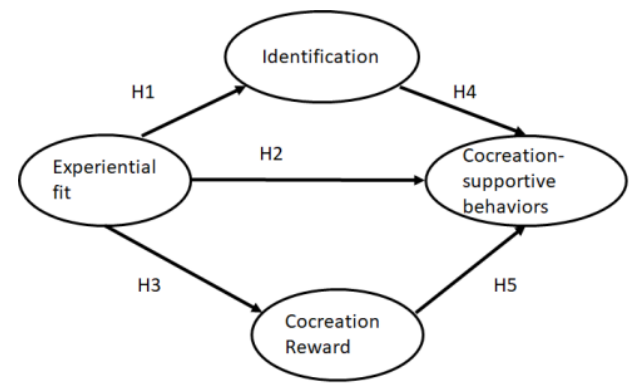

Fig.1: Conceptual framework

\section{Methodology}

\subsection{Survey Respondents}

Vietnamese college students and US Amazon Mechanical Turk (Mturk) workers are selected as respondents. A screening question was used to target the sample respondents, who had to have participated in a popular ecosystem using a mobile app of Amazon, Uber, Lyft, Netflix, Tiki, Shopee, Lazada, or Grab.

Convenience sampling was used for data collection because the authors are instructors in the respondents' university. A total of 520 valid Vietnamese responses were collected. In addition to the Vietnamese students, 609 responses from workers at MTurk, a crowdsourcing marketplace with a diverse and flexible workforce, were collected. Finally, a total of 1,090 valid responses (i.e., 497 from the Vietnamese students and 593 from MTurk workers) remained for data analysis.

\subsection{Survey Measurement}

The construct items are adapted from prior studies and modified to conform to the context. The survey items are measured using a 7-point Likert scale in which 1 indicated "strongly disagree" and 7 "strongly agree." Experiential fit is measured using items adopted from the information system success model [47]. The dimension of emotion is added, as suggested in a prior study [48]. Identification with a social category creates social and psychological ties among individuals and organisations [34, 35]. [49]) illustrated a concept of identification that is induced by group interdependence through a joint task, goal, or reward. Although our study adopts general identification [49], we create a single-item scale for the purpose of separating the concept from rewards, achievement, and supportive activities. Individuals, including platform members and customers, are driven to actively exchange knowledge and to interact through links and postings and therefore maintain the ecosystem community [50] and increase the contribution behaviours of others [51] This is the dimension of cocreation-supportive behaviours that has been developed in prior studies [52-54]. Cocreation reward is measured using items adopted from Busser and Shulga [55]. The respondents are instructed to assume that they are invited to participate in a fictional project conducted by the ecosystem. The survey introduces them to the hypothetical project as follows to verify that they are aware with the notion of cocreation rewards: Assume you've been recruited to collaborate on a project by the ecosystem company mentioned before. To advertise its new cashless service, the project entails cocreation of content in the form of a marketing video clip. What words would you use to characterize this experience?

\subsection{Structural Equation Modelling}

SPSS and AMOS version 22 are used to analyse the data. We combine the two samples in the data analysis. First, both samples consist of active digital business users who had experience of ecosystem business platforms and therefore were likely to be able to generate cocreation-related behaviours. Second, most of the proposed research constructs are related to and relevant for both samples. The combined sample would benefit the generalisability of the findings. Business ecosystems include diverse people whose demographic profiles may vary. Third, the samples both have respondents who were similarly open to popular digital platforms.

\section{Data Analysis and Results}

4.1 Descriptive Statistics and Measurement Model-Confirmatory Factor Analysis 
The results reveal adequate qualification and validity for further testing (Table 1). The standardised indicator loadings are suggested to be higher than 0.60 [56]. Three general indicatorscomposite reliability (CR), average variance extracted (AVE), and Cronbach's alpha - are used to measure construct reliability and convergent validity [57]. CR should be equal to or greater than 0.70 [58]. The AVE should be greater than 0.50 [59], and Cronbach's alpha should meet the 0.70 threshold [60].

Table 1. Description, reliability, and discriminant validity

\begin{tabular}{lcccc}
\hline $\begin{array}{l}\text { Construct } \\
\text { items }\end{array}$ & $\begin{array}{l}\text { Factor } \\
\text { loadings }\end{array}$ & AVE & CR & $\begin{array}{l}\text { Cronbach } \\
\text { Alpha }\end{array}$ \\
\hline Experiential fit & & 0.544 & 0.722 & 0.804 \\
EF1 & 0.756 & & & \\
EF2 & 0.758 & & & \\
EF3 & 0.774 & & & \\
EF4 & 0.656 & & & \\
\hline
\end{tabular}

Identification

ID1 0.74

\begin{tabular}{|c|c|c|c|c|}
\hline \multicolumn{2}{|c|}{$\begin{array}{l}\text { Cocreation-supportive } \\
\text { behaviors }\end{array}$} & 0.502 & 0.717 & 0.822 \\
\hline SB1 & 0.763 & & & \\
\hline SB2 & 0.781 & & & \\
\hline SB3 & 0.767 & & & \\
\hline SB4 & 0.687 & & & \\
\hline SB5 & 0.607 & & & \\
\hline Cocreation reward & & 0.641 & 0.851 & 0.886 \\
\hline CR1 & 0.793 & & & \\
\hline $\mathrm{CR} 2$ & 0.869 & & & \\
\hline CR3 & 0.893 & & & \\
\hline CR4 & 0.784 & & & \\
\hline CR5 & 0.638 & & & \\
\hline
\end{tabular}

Note: Cronbach's alpha and CR are not provided for single-indicator constructs.

Common measures - namely the ratio of $\chi^{2}$ statistics to the degree of freedom (df), comparative fit index (CFI), goodness-of-fit index (GFI), adjusted goodness-of-fit index (AGFI), normed fit index (NFI), incremental fit index (IFI), TuckerLewis index (TLI), standardised root mean squared residual (SRMR), and root mean square error of approximation (RMSEA) - are used to evaluate the measurement model's goodness of fit. The confirmatory factor analysis results indicate significant convergent validity of all estimated factor loadings. The $\chi^{2}$ is 1175.51 , and the $\mathrm{df}$ is 266 $(p<0.001)$; moreover, $\chi^{2} / \mathrm{df}$ is 4.419 , which is acceptable. The CFI is 0.935 , the GFI is 0.911 , and the NFI is 0.918 , all greater than the suggested threshold level of 0.9. The RMSEA is 0.056, thus less than 0.1 [61] as suggested by [62]. The SRMR is 0.047 , less than 0.1 as suggested by [63]. All the measures indicate the model's acceptability.

Table 2. Pearson correlation coefficients

\begin{tabular}{|c|c|c|c|c|c|c|c|c|c|}
\hline & Gender & Age & Edu & Occu & Usehrs & ExFit & CoRe & Iden & SupCo \\
\hline Gender & -- & & & & & & & & \\
\hline Age & $0.196^{* \prime}$ & & & & & & & & \\
\hline Edu & $0.094^{* \prime}$ & $0.377^{* *}$ & & & & & & & \\
\hline Occu & $-0.261^{* t}$ & $\overline{0.535^{* *}}$ & $\overline{0} .305^{* *}$ & & & & & & \\
\hline Usehrs & -0.049 & $\bar{x}_{0.142^{* *}}$ & $\overline{0}_{0.062^{*}}$ & $0.272^{* *}$ & & & & & \\
\hline ExFit & -0.045 & 0.039 & $0.087^{* *}$ & -0.007 & $0.088^{* *}$ & $(0.80)$ & & & \\
\hline CoRe & $-0.104^{*}$ & 0.007 & $0.087^{* *}$ & 0.046 & $0.099^{* *}$ & $0.586^{* *}$ & $(0.83)$ & & \\
\hline Iden & -0.011 & -0.011 & $0.089^{* *}$ & 0.05 & $0.113^{* *}$ & $0.565^{* *}$ & $0.382^{* *}$ & -- & \\
\hline SupCo & $-0.099^{* *}$ & -0.017 & $0.081^{* *}$ & $0.081^{* *}$ & $0.178^{* *}$ & $0.677^{* *}$ & $0.684^{* *}$ & $0.539^{* *}$ & $(0.76)$ \\
\hline Mean & 0.46 & 2.59 & 2.28 & 5.06 & 3.4 & 5.41 & 5.64 & 5.21 & 5.44 \\
\hline SD & 0.5 & 1.51 & 0.62 & 2.93 & 1.71 & 0.96 & 1.01 & 1.35 & 0.96 \\
\hline
\end{tabular}

Note: $* \mathrm{p}<0.05, * * \mathrm{p}<0.01, \mathrm{SD}=$ standard deviation, Usehrs $=$ hours of app usage per week, ExFit $=$ experiential fit, Iden $=$ identification, CoRe $=$ cocreation reward, SupCo $=$ cocreation-supportive behaviours. The square root of the AVE is in parentheses. The numbers in parentheses are all higher than the corresponding off-diagonal elements.

\subsection{Common Method Variance}

Because a cross-sectional survey method is used, we select two indicators to test for common method variance (CMV) and ensure data validity and quality. To examine the CMV, Harman's one-factor test is applied. The Harman's strategy for identifying CMV suggests that if a single component or a generic factor emerges as accounting for the bulk of the covariance among the measures, it is inferred that there is a significant degree of common method variation. The results reveal that the first construct accounts for only $20.95 \%$ of the variance, indicating that common method bias is unlikely to be a concern [64]. In addition, the Pearson correlation matrix was employed to identify strongly correlated factors [65]. CMV is a concern when an uncommonly strong correlation is found $(r>0.9$, other than square root of the AVE). The correlation analysis results in the correlation table do not report such an incident. Our data are concluded to be relatively robust against CMV.

\subsection{Structural Model and Path Coefficient Analysis}


We perform structural equation modeling (SEM) using AMOS 22 to generate the coefficients in our research framework. Structural equation modeling is a multivariate data analysis approach for analyzing structural connections. The structural connection between measured variables and latent constructs is examined using this approach, which combines component analysis and multiple regression analysis. The overall model fit is adequate $\left(\chi^{2}=\right.$ $391.384, \mathrm{df}=100, p=0.000, \chi^{2} / \mathrm{df}=3.914$, SRMR $=0.040, \mathrm{GFI}=0.956, \mathrm{NFI}=0.952, \mathrm{CFI}=0.964$, and RMSEA $=0.052$ ). The framework-fit indicators surpass the acceptable levels and represent a fit to the data $[61,63,62]$.

Experiential fit explains $35 \%$ of the variance in identification and $47.3 \%$ of that in cocreation reward. Identification and cocreation reward explain $79.8 \%$ of the variance in platform cocreationsupportive behaviours. The relationships of experiential fit with identification $(\beta=0.592, \mathrm{t}=$ $6.279, p=0.000)$, cocreation reward $(\beta=0.688, \mathrm{t}=$ $11.488, p=0.000)$, and supportive behaviours $(\beta=$ $0.419, \mathrm{t}=6.667, p=0.000)$ are positive and significant, as is the relationship between identification and supportive behaviours $(\beta=0.162$, $\mathrm{t}=6.667, p=0.000)$ and that between cocreation reward and supportive behaviours $(\beta=0.441, \mathrm{t}=$ 6.667, $p=0.000$ ). Thus, $\mathrm{H} 1, \mathrm{H} 2$, and $\mathrm{H} 3$ are supported. According to these results, identification increases the levels of cocreation-supportive behaviours $(\beta=0.100, \mathrm{t}=3.541, p=0.000)$, as does cocreation reward $(\beta=0.422, \mathrm{t}=11.552, p=0.000)$. Thus, $\mathrm{H} 4$ and $\mathrm{H} 5$ are supported.

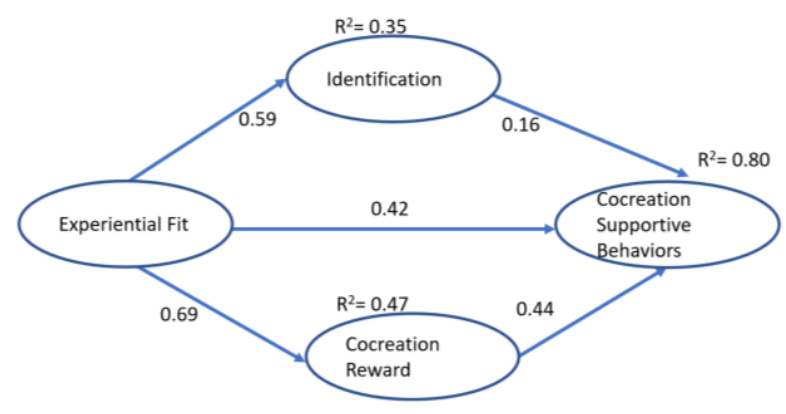

Fig.2: Summary of SEM paths.

\section{Data Analysis and Results}

Despite growing interest in ecosystems, the lack of studies on how individual experiential fit influences ecosystem platform cocreation indicates a need for more research. To more thoroughly understand how the individual dynamics of mobile apps affect cocreation-supportive behaviours, we develop and test a process model by including sequential mediators. We integrate recent organisational fluidity research and theories regarding value congruence (i.e., experiential fit), value reservation and achievement (i.e., cocreation reward, identification), and value dissemination (i.e., cocreation-supportive behaviours). This servicefocused study conceptualises a service as value creation and delivery through the application of expertise and knowledge to support other parties. The ecosystem is the service integration of value and resources. Ecosystem dynamics mobilise the implicit value, fit it to user experience, and reserve, and deliver it to actors, users, and audiences. Organised on the ecosystem platform, business activities enhance the flexible combination of resources and value to create new assets that are the sources of innovation [6]. Our study reveals that the compatibility of user expectations with platform experience helps develop design quality, and it predicts identification, cocreation rewards, and supportive behaviours and thus improves the sustainability of firms in the ecosystem $[55,66,30]$. In particular, experiential fit, identification, and cocreation reward successfully form the mechanism in the setting of ecosystem cocreation value.

\section{Conclusions, Implications, and Future research}

\subsection{Theoretical Implications}

This study sheds lights to the literature on business SD enabling fluidity and supportive activities in several aspects. It uncovers the connection between ecosystem suitable functionalities and fluidity. The study was inspired by the idea that better understanding of this phenomenon would help people, communities, companies, and society as a whole foster successful, supportive ecosystem.

First, this study suggests a focus on the design of platform experience in response to user expectations in the modern digital age. Specifically, the design of a mobile-based app platform for experimenting with big data should meet customer expectations, favourably forecast market trends, and improve business efficiency. Empowered by the growth of ecosystem platforms and consumer dynamics, the mechanisms underlying smartphone apps should ensure that users' expectations of their experience converge with platform technical tasks to strengthen a business's market position. Information, service, and system experience can conform to prevailing and unique individual 
lifestyles and preferences. A high degree of fluidity between the tasks and functional experiences of platform users can encourage unique, unstructured characteristics.

Second, our study decodes value dissemination to obtain supportive behaviours through cocreation rewards in the ecosystem. Value dissemination is driven by platform identification (and thus is connected, cohesive, strongly tied, and secured) and project-based cocreation rewards (as defined by meaningfulness, contribution, collaboration, affect, and recognition). We contribute a novel clarification of the notable effects of identification and cocreation rewards on an ecosystem firm's cocreation.

This study empirically confirms identification and cocreation reward as significant predictors of platform cocreation-supportive behaviours. Value is embedded in the form of data that can be leveraged by both the demand and supply sides. The promise of value achievement (cocreation reward) and value reservation (identification) may encourage users and customers to contribute to ecosystem services. Remarkably, the experiential fit-cocreation reward relationship rather than the experiential fitidentification relationship plays a critical role in mediating the relationship between user mobilitysupportive behaviours for platform cocreation. When using digital platforms, customers raise their reward consciousness rather than their belongingness because of the fluid value of the cocreation progress. Studies have revealed that consumers are value consumption beneficiaries [67] and value integrators [5]. Our study redefines the concept of the platform consumer as a value producer given their ability to achieve, reserve, and disseminate value and to maintain sustainable ecosystem cocreation. These attributes require a focus on user and customer motivation to become value producers.

\subsection{Managerial Implications}

In the landscape of a business ecosystem, firms may not play the same role they play in traditional markets. The journey with end users and customers is dependent on highly experiential fit and discrete value compositions related to the ecosystem platform. New mobility strategies consider users as a source of an enormous amount of cocreation diverse data. Digital platform administrators may take advantage of user-generated big data to develop dominant value-capturing instruments for the entire ecosystem [68]. Mobile Information Communication Technology (ICTs) capabilities allow mobile devices to blend effortlessly into the human community, rather than forcing people into a virtual universe of machines and technology. Interoperability is vital to maximising the advantages of mobile ICTs.

First, the results of this study can help managers formulate strategies to improve the quality of their firm's cocreation projects with ecosystem platform partners. The fluidity of mobile ecosystems enables organisational support of cocreation activities. The conception of the coexistence of close identification and flexible rewards in effort empowered by mobile ICTs can be insightful when scheming and applying mobile technologies and organising the users. For example, common goals and interdependencies among users, microproviders, and platform firms should expand and generate new value for the ecosystem's operations, and the uniqueness of user experiences can serve as a critical driver of platform dynamics for improved processes.

Second, our study proposes increased effort and investment in open innovation of ecosystem platforms of encouraging cocreation. If contemporary ecosystem firms are designing activities, in terms of appropriate (fluid) incentives, identification, and the supporting team, this study provides an operation plan of what the firms should use and what activities should be suitable so that capabilities are enhanced. Platform applications can effortlessly blend into human lifestyles if the ecosystem firms have those capabilities. Thus, ecosystem participants may have the motivation to increase their dynamic capability and to engage with new partners for cocreation and innovation, thus moving beyond traditional research and development. For example, Grab Reward program involves increasing its users and customers and thereby boosts supportive behaviours. Grab, one of the Southeast Asia's ecosystem mobile network, unveiled GrabRewards program as well as new collaborations with their customers to gain new creation. From experiencing different services including delivery and transportation, Grab attracted customers to their rewards which iniatives their customer to produce a video with the purpose of spreading new word-of-mouth and advertising messages. Between the two predictors of cocreationbased identification and rewards, cocreation reward more accurately forecasts cocreation-supportive behaviours, sustainable development, and other contributions of ecosystem firms than identification does. Specifically, as a big data and machine learning method $[69,70]$ to enhance the consumer cocreation behaviors, beyond the loyalty and identity with the ecosystem, reward programs 
should be developed to include a variety of experiential incentives.

\subsection{Research Limitations and Future Work}

Our study has restrictions that should be addressed in future research. First, in Vietnam, the study only examines students. Vietnam is an emerging country and is characterised by its middle-income status, young population, fast-growing economy, and rapid demographic and social changes. Future studies should consider different contexts and cultures to diversify the scope of research and develop improved ecosystem strategies. Second, the use of single-dimensional identification as a measure for value reservation has some limitations because it was originally developed for community settings. However, identification is a widely used measure for online services and businesses, and the results reveal its significant mediating role in the model. Finally, future studies could examine cocreation activities in different settings of business ecosystem platforms that have various technological capabilities. We limit our investigation to the context of ecosystem platforms and the individual level. However, the notion of the ecosystem platform can also be used to discuss multiple industries and socioeconomic activities such as social media, health, and finance. In light of fluidity theory, SD logic, and the social support perspective, further studies can compare different settings related to digital business ecosystems with regard to problems related to fit, identification, and reward.

\section{References:}

[1] Atluri, V., M. Dietz, and N. Henke, "Winning in digital ecosystems". Digital/McKinsey: Insights, 2018: p. Retrieved from https://www.mckinsey.com/industries/financial -services/our-insights/insurance-beyonddigital-the-rise-of-ecosystems-and-platforms\#.

[2] Statista, "Total global mobile app revenues 2014-2023". 2018: p. Retrieved from https://www.statista.com/statistics/269025/worl dwide-mobile-app-revenue-forecast/.

[3] Roma, P. and M. Vasi, "Diversification and performance in the mobile app market: The role of the platform ecosystem". Technological Forecasting and Social Change, 2019. 147: p. 123-139.

[4] Zervas, G., D. Proserpio, and J.W. Byers, "The rise of the sharing economy: Estimating the impact of Airbnb on the hotel Industry". Journal of Marketing Research, 2017. 54(5): p. $687-705$.
[5] Lusch, R. and S. Nambisan, "Service innovation: A service-dominant logic perspective". MIS Quarterly, 2015. 39(1): p. 155-175.

[6] Lusch, R.F. and S.L. Vargo, "The servicedominant logic: Premises, perspectives, possibilities". Cambridge, UK: Cambridge University Press, 2014.

[7] Vargo, S.L., H. Wieland, and M.A. Akaka, "Innovation through institutionalization: A service ecosystems perspective". Industrial Marketing Management, 2015. 44: p. 63-72.

[8] Bettencourt, L., R. Lusch, and S. Vargo, "A service lens on value creation: Marketing's role in achieving strategic advantage". California Management Review, 2014. 57: p. 44-66.

[9] Cheng, X., J. Krönung, and A. Zarifis, "Collaborative consumption for low and high trust requiring business models: from fare sharing to supporting the elderly and people with disability". International Journal of Electronic Business, 2019. 15: p. 1.

[10] Xie, K., et al., "Value co-creation between firms and customers: The role of big data-based cooperative assets". Information \& Management, 2016. 53: p. 1034-1048.

[11] Lugosi, P., "Mobilising identity and culture in experience co-creation and venue operation". Tourism Management, 2014. 40: p. 165-179.

[12] Leung, L., "Exploring the relationship between smartphone activities, flow experience, and boredom in free time". Computers in Human Behavior, 2020. 103: p. 130-139.

[13] Chatterjee, S., S. Sarker, and M. Siponen, "How do mobile ICTs enable organizational fluidity: Toward a theoretical framework". Information \& Management, 2017. 54(1): p. 113.

[14] Adner, R., "Ecosystem as structure: An actionable construct for strategy". Journal of Management, 2016. 43(1): p. 39-58.

[15] Jacobides, M.G., C. Cennamo, and A. Gawer, "Towards a theory of ecosystems". Strategic Management Journal, 2018. 39: p. 2255 2276.

[16] Grabowski, M. and K.H. Roberts, "Risk mitigation in virtual organizations". Organization Science, 1999. 10(6): p. 704-721.

[17] Marra, A. and P. Antonelli, "Social commerce: a taxonomy and cross-component investigation of business practices and technological choices". International Journal of Electronic Business, 2018. 14(4): p. pp.352 - 370.

[18] Faraj, S., S.L. Jarvenpaa, and A. Majchrzak, "Knowledge collaboration in online 
communities". Organization Science, 2011. 22(5): p. 1224-1239.

[19] Cova, B., D. Dalli, and D. Zwick, "Critical perspectives on consumers' role as 'producers': Broadening the debate on value co-creation in marketing processes". Marketing Theory, 2011. 11(3): p. 231-241.

[20] Vargo, S.L. and R.F. Lusch, "Evolving to a new dominant logic for marketing". Journal of Marketing, 2004. 68: p. 1-17.

[21] Fachrunnisa, O. and F. Hussain, "A methodology for creating sustainable communities based on dynamic factors in virtual environments". International Journal of Electronic Business, 2020. 15: p. 133.

[22] Huang, K.-Y., I. Chengalur-Smith, and A. Pinsonneault, "Sharing is caring: social support provision and companionship activities in healthcare virtual support communities". MIS Quarterly, 2019. 43(2): p. 395-424.

[23] Prahalad, C.K. and V. Ramaswamy, "Coopting Customer Competence". Havard Business Review, 2000. 78(1): p. 79-90.

[24] Gensler, S., et al., "Managing brands in the social media environment". Journal of Interactive Marketing, 2013. 27(4): p. 242-256.

[25] Gronroos, C. and P. Voima, "Critical service logic: making sense of value creation and cocreation". Journal of Academy of Marketing Science, 2013. 41(2): p. 133-150.

[26] Oestreicher-Singer, G. and L. Zalmanson, "Content or community? A digital business strategy for content providers in the social age". MIS Quarterly, 2013. 37(2): p. 591-616.

[27] Hernández-Ortega, B. and J.L. Franco, "Developing a new conceptual framework for experience and value creation". Service Business, 2019. 13(2): p. 225-248.

[28] Kosalge, P., S. Crampton, and A. Kumar, "Blogs: Are they headed downwards in social networking? An empirical analysis". International Journal of Electronic Business, 2019. 15: p. 72.

[29] Rink, F. and N. Ellemers, "Diversity as a basis for shared organizational identity: The norm congruity principle". British Journal of Management, 2007. 18(1): p. 17-27.

[30] Wiesenfeld, B.M., S. Raghuram, and R. Garud, "Organizational identification among virtual workers: The role of need for affiliation and perceived work-based social support". Journal of Management, 2001. 27(2): p. 213-229.

[31] Wareham, J., P.B. Fox, and J.L. Cano-Giner, "Technology Ecosystem Governance".
Organization Science, 2014. 25(4): p. 11951215.

[32] Dey, B.L., D. Yen, and L. Samuel, "Digital consumer culture and digital acculturation". International Journal of Information Management, 2020. 51: p. 102057.

[33] Zammuto, R.F., et al., "Information technology and the changing fabric of organization". Organization Science, 2007. 18(5): p. 749-762.

[34] Davenport, S. and U. Daellenbach, "Belonging to a virtual research centre: Exploring the influence of social capital formation processes on member identification in a virtual organization". British Journal of Management, 2011. 22(1): p. 54-76.

[35] Wiesenfeld, B.M., S. Raghuram, and R. Garud, "Communication patterns as determinants of organizational identification in a virtual organization". Organization Science, 1999. 10(6): p. 777-790.

[36] Ma, M. and R. Agarwal, "Through a glass darkly: Information technology design, identity verification, and knowledge contribution in online communities". Information Systems Research, 2007. 18(1): p. 42-67.

[37] Yoo, Y., et al., "Organizing for Innovation in the Digitized World". Organization Science, 2012. 23(5): p. 1398-1408.

[38] Chiu, C.-M., M.-H. Hsu, and E.T.G. Wang, "Understanding knowledge sharing in virtual communities: An integration of social capital and social cognitive theories". Decision Support Systems, 2006. 42(3): p. 1872-1888.

[39] Bateman, P.J., P.H. Gray, and B.S. Butler, "The impact of community commitment on participation in online communities". Information Sytems Research, 2011. 22(4): p. 841-854.

[40] Yoon, S. and E.-M. Lee, "Social and psychological determinants of value cocreation behavior for South Korean firms: A consumer-centric perspective". Asia Pacific Journal of Marketing and Logistics, 2019. 31(1): p. 14-36.

[41] Franke, N. and S.K. Shah, "How communities support innovative activities: An exploration of assistance and sharing among end-users". Research Policy, 2003. 32(1): p. 157-178.

[42] McWilliam, G., "Building strong brands through online communities". Sloan Management Review, 2000. 41(13): p. 43-54.

[43] Edvardsson, B., B. Tronvoll, and T. Gruber, "Expanding understanding of service exchange and value co-creation: A social construction 
approach". Journal of the Academy of Marketing Science, 2011. 39(2): p. 327-339.

[44] Payne, A.F., K. Storbacka, and P. Frow, "Managing the co-creation of value". Journal of the Academy of Marketing Science, 2008. 36(1): p. 83-96.

[45] Roggeveen, A.L., M. Tsiros, and D. Grewal, "Understanding the cocration effect: When does collaborating with customers provide a lift to service recovery?". Journal of the Academy of Marketing Science, 2012. 40(6): p. 771-790.

[46] Kumar, V. and D. Shah, "Expanding the role of marketing: From customer equity to market capitalization". Journal of Marketing, 2009. 73(6): p. 119-136.

[47] DeLone, W.H. and E.R. McLean, "The DeLone and McLean model of information systems success: A ten year update". Journal of Management Information Systems, 2003. 19(4): p. 9-30.

[48] Russell, J.A., L.M. Ward, and G. Pratt, "Affective quality attributed to environments: A factor analytic study". Environment and Behavior, 1981. 13(3): p. 259-288.

[49] Ren, Y., et al., "Building member attachment in online communities: Applying theories of group identity and interpersonal bonds". MIS Quarterly, 2012.36(3): p. 841-864.

[50] Hsu, C.L. and J.C.C. Lin, "Acceptance of blog usage: The roles of technology acceptance, social influence and knowledge sharing motivation". Information \& Management, 2008. 45(1): p. 65-75.

[51] Silva, L., L. Goel, and E. Mousavidin, "Exploring the dynamics of blog communities: The case of MetaFilter". Information Systems Journal, 2009. 19(1): p. 55-81.

[52] Bettencourt, L.A., "Customer voluntary performance: Customers as partners in service delivery". Journal of Retailing, 1997. 73(3): p. 383-406.

[53] Groth, M., "Customers as good soldiers: Examining citizenship behaviors in internet service deliveries". Journal of Management, 2005. 31(7): p. 7-27.

[54] Yi, Y., R. Nataraajan, and T. Gong, "Customer participation and citizenship behavioral influences on employee performance, satisfaction, commitment, and turnover intention". Journal of Business Research, 2011. 64(1): p. 87-95.

[55] Busser, J.A. and L.V. Shulga, "Co-created value: Multidimensional scale and nomological network". Tourism Management, 2018. 65: p. 69-86.

[56] Hair, J.F., et al., eds. "Multivariate data analysis". 1998, Prentice Hall: Upper Saddle River, NJ.

[57] Malhotra, N.K. and S. Dash, "Marketing Research an Applied Orientation". 2011: London Pearson Publishing.

[58] Fornell, C. and D.F. Larker, "Evaluating structural equation models with unobservable variables and measurements error". Journal of Marketing Research, 1981. 18(1): p. 39-50.

[59] Chin, W.W., "Commentary: Issues and opinion on structural equation modeling". MIS Quarterly, 1998. 22(1): p. vii-xvi.

[60] Nunally, J.C., "Psychometric Theory". 1978, New York, United States of America: McGraw-Hill.

[61] Bagozzi, R.P. and Y. Yi, "On the evaluation of structural equation models". Journal of the Academy of Marketing Science, 1988. 16(1): p. 74-94.

[62] Dinh, T.H., B. Igel, and T. Laosirihongthong, "The impact of total quality management on innovation: Findings from a developing country". International Journal of Quality \& Reliability Management, 2006. 23(9): p. 10921117.

[63] Browne, M.W. and R. Cudeck, "Alternative ways of assessing model fit". Sociological Methods \& Research, 1992. 21(2): p. 230-258.

[64] Podsakoff, P.M., et al., "Common method biases in organizational research: A critical review of the literature and recommended remedies". Journal of Applied Psychology, 2003. 88(1): p. 879-903.

[65] Bagozzi, R.P. and Y. Yi, "On the use of structural equation models experimental designs". Journal of Marketing Research, 1989. 26(3): p. 271-284.

[66] DeLone, W.H. and E.R. McLean, "Measuring e-commerce success: Applying the DeLone and McLean information systems success model". International Journal of Electronic Commerce, 2004. 9(1): p. 31-47.

[67] Macdonald, E.K., et al., "Assessing value-inuse: A conceptual framework and exploratory study". Industrial Marketing Management, 2011. 40(5): p. 671-682.

[68] Trabucchi, D. and T. Buganza, "Fostering digital platform innovation: From two to multisided platforms". Creativity and Innovation Management, 2020. 29(2): p. 345-358.

[69] Meshref, H., "Predicting Loan Approval of Bank Direct Marketing Data Using Ensemble 
Machine Learning Algorithms". International Journal of Circuits, Systems and Signal Processing, 2020. 14: p. 914-922.

[70] Wang, Z., "Research on E-commerce Payment Security and Privacy Protection based on Improved B2C Model". International journal of circuits, systems and signal processing, 2020. 14: p. 520-525.

Contribution of Individual Authors to the Creation of a Scientific Article (Ghostwriting Policy)

Author Contributions:

My-Trinh Bui wrote the paper and carried out data collection.

Don Jyh-Fu Jeng has implemented the design of methodology; creation of models.

Thi Mai Le has analyzed the surveyed data.

\section{Sources of Funding for Research Presented} in a Scientific Article or Scientific Article Itself

This research is funded by International School, Vietnam National University, Hanoi (VNU-IS) under project number KHCN_2019.01.

Creative Commons Attribution License 4.0 (Attribution 4.0 International, CC BY 4.0)

This article is published under the terms of the Creative Commons Attribution License 4.0 https://creativecommons.org/licenses/by/4.0/deed.en _US 